\title{
Spremljanje vektorjev borove ogorčice (Monochamus spp.) in druge entomofavne v Sloveniji od leta 2007 do leta 2013
}

\author{
Maja JURC*, Roman PAVLIN, Gregor METERC, Danijel BORKOVIČ
}

Borova ogorčica Bursaphelenchus xylophilus (Steiner in Buhrer) Nickle lahko $\mathrm{v}$ enem vegetacijskem obdobju povzroči odmiranje borov (Pinus spp.) vseh starostnih razredov. V Sloveniji in državah Evropske unije je vrsta uvrščena na A1 listo karantenskih škodljivih organizmov. Izvira iz Severne Amerike, od koder je bila zanesena v azijske države, leta 1999 pa so jo ugotovili v Evropi na Portugalskem, kjer je bila najdena na vrsti Pinus pinaster. V naravi za širjenje potrebuje vektorje, to so kozlički rodu Monochamus. Zaradi nevarnosti vnosa in hitrega širjenja ter velikih ekonomskih in ekoloških škod, ki jih v Aziji in Evropi povzroča borova ogorčica, izvajamo Posebni nadzor borove ogorčice v Sloveniji v skladu z Zakonom o zdravstvenem varstvu rastlin (Uradni list RS, št. 45/01) in Odločbo Komisije 2006/133/EC ki zahteva, da države članice začasno sprejmejo dodatne ukrepe proti širjenju borove ogorčice B. xylophilus. Po standardu PM 9/1 (4) 2011 je $\mathrm{v}$ državah EU obvezno spremljanje tudi vektorjev borove ogorčice.

$\mathrm{Z}$ monitoringom in raziskavami kozličkov iz rodu žagovinarjev ter drugo spremljajočo entomofavno smo začeli leta 2007 in nadaljujemo še danes. Lokacije, kjer so bile opravljene raziskave, so prikazane na sliki 1. Z ekologijo in kemijsko biologijo žagovinarjev smo se ukvarjali med letoma 2007 in 2009 na osmih lokacijah v sestojih Pinus nigra, P. sylvestris, $P$. halepensis, Picea abies in Abies alba. Entomofavna je bila lovljena $\mathrm{s}$ črnimi križnimi (»cross-vane«) pastmi (štiri pasti/lokacija), ki so bile nameščene na pribl. 1,5 m nad tlemi - mokri ulov $\mathrm{z}$ atraktanti (etanol $+\alpha$-pinen, sproščanje okoli $2 \mathrm{~g} /$ dan pri $25-28^{\circ} \mathrm{C}$ ), Pheroprax ${ }^{\circledR}$ in Gallowit ${ }^{\circledR}$ ). Ulovljenih je bilo 94 vrst hroščev (Coleoptera), ki so pripadali štiriindvajsetim družinam. V ulovu so prevladovali podlubniki (Scolytinae) s 76,55 \%, predstavnikov družine kozličkov (Cerambycidae) je bilo $8,12 \%$, predstavnikov družine Curculionidae pa $1,67 \%$. Nabranih je bilo 24 različnih taksonov kozličkov, med katerimi so bile najpogostejše vrste Spondylis buprestoides (Linnaues, 1758), Arhopalus rusticus (Linnaues, 1758), Monochamus galloprovincialis (Olivier, 1795) in Arhopalus ferus (Mulsant, 1839). Med žagovinarji je bil največji ulov vrste $M$. galloprovincialis s $17,54 \%$, sledil je $M$. sutor z $0,09 \%$ in $M$. sartor z $0,04 \%$.

V letih 2010 in 2013 smo nadaljevali monitoring in raziskave biologije-fenologije žagovinarjev na petih lokacijah v sestojih $P$. nigra, $P$. halepensis, $P$. sylvestris, A. alba in P. abies. Leta 2011 smo začeli uporabljati nov atraktant GalloProtect $2 \mathrm{D}^{\circledR}$, za primerjavo uspešnosti ulova pa še $\alpha$-pinen+etanol, pasti so bile nameščene $v$ krošnje dreves. Rezultati so pokazali, da je metoda uporabe atraktanta GalloProtect $2 \mathrm{D}^{\circledR}$ in namestitev pasti v krošnje dreves bolj ustrezna kot pred tem uporabljena metoda, saj se je ulov žagovinarjev povečal. Zaradi kairomonskega porekla atraktanta GalloProtect $2 \mathrm{D}^{\circledR}$ pa je bilo v ulovu tudi veliko naravnih sovražnikov podlubnikov, zlasti iz družine Cleridae. Na lokaciji Brdo je bilo v letih 2010 in 2011 ulovljenih 113 vrst hroščev, ki pripadajo 32 družinam. Ugotovili smo prisotnost štirih vrst žagovinarjev (M. galloprovincialis, $M$. sutor, $M$. sartor in $M$. sultuarius), kar je največ v Evropi (slika 2 in 3). Raziskovali smo njihovo bionomijo in ekologijo, kar predstavlja pomembno podlago gospodarjenja $\mathrm{v}$ sestojih iglavcev pri morebitnem vnosu borove ogorčice v Slovenijo. Poleg tega smo našli nekatere redke predstavnike naše saproksilne entomofavne in odkrili nekatere tujerodne in invazivne vrste hroščev. Raziskali smo tudi vrstno sestavo družin hroščev, ki vključujejo naravne sovražnike podlubnikov (Histeridae, Trogossitidae, Cleridae, Nitidulidae, Monotomidae, Zopheridae, Tenebrionidae in Salpingidae). Ujeti hrošči iz družine Cleridae, kot so Thanasimus formicarius, $T$. femoralis in Clerus mutillarius, bi lahko bili zanimivi za razvoj biotičnih metod integralnega varstva gozda.

\section{Zahvala}

Zahvaljujemo se kolegom iz ZGS, ki so sodelovali pri izbiri ustreznih lokacij za naše raziskave: Mladen Prebevšek, Branka Gasparič, Boštjan Košiček in revirni gozdarji.Raziskave so bile opravljene v okviru financiranja programske skupine P4-0059 Gozd, gozdarstvo in obnovljivi gozdni viri (1.1.1999-31.12.2014) ter raziskovalnih projektov LIFE09ENV/IT/000078 "Managing forests for multiple purposes: carbon, biodiversity and socio-economic wellbeing", št.: MOP 2311-11-000060 (2010-2013) in V4-1075 Ogroženost naših gozdov zaradi borove ogorčice Bursaphelenchus xylophilus (1.10.2010-30.9.2013).

\section{Viri}

EPPO, 2011. Bursaphelenchus xylophilus and its vectors: procedures for official control. EPPO Bulletin, 41: 377-384. doi: 10.1111/j.1365-2338.2011.02506.x

Jurc M., Bojovic S., Fernández M., Jurc D. 2012. The attraction of cerambycids and other xylophagous beetles, potential vectors of Bursaphelenchus xylophilus, to semio-chemicals in Slovenia. Phytoparasitica, 40, 4: 337-349. doi: 10.1007/s12600-012-0234-4

Jurc M., Bojovic S., Pavlin R., Metrec G., Repe A., Borkovic D., Jurc D. 2012. Biodiversity of saproxylic beetles of pine forests in Slovenia with emphasis on Monochamus species. In: Jurc M. (ur.). Saproxylic beetles in Europe: monitoring, biology and conservation, (Studia forestalia Slovenica, 137). Ljubljana: Slovenian Forestry Institute, Silva Slovenica: 23-32.

Pavlin R., Meterc G., Borkovič D., Jurc M. 2012. Biodiversity of entomofauna in the red pine forest of the Brdo estate regarding to different sampling methods used. V: $7^{\text {th }}$ Symposium and Workshop on the Conservation of Saproxylic Beetles, 12.-14. 5. 2012, Granada Spain. Granada, Universidad de Granada, Universidad Rey Juan Carlos: 22.

*Univerza v Ljubljani, Biotehniška fakulteta, Oddelek za gozdarstvo in obnovljive gozdne vire Večna pot 83, 1000 Ljubljana maja.jurc@bf.uni-lj.si 


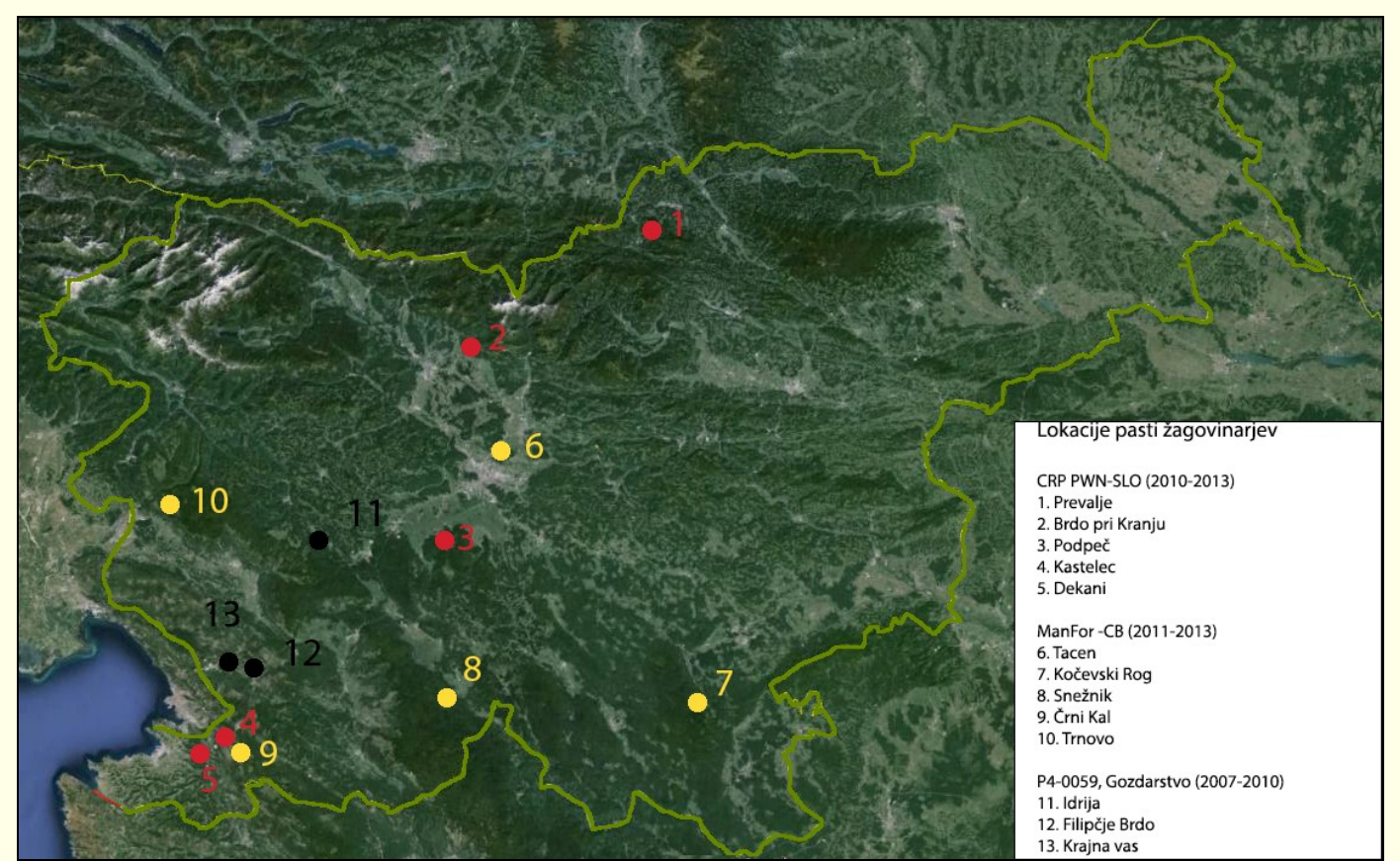

Slika 1: Lokacije raziskav kozličkov iz rodu žagovinarjev (Monochamus spp.) in spremljajoče entomofavne v Sloveniji v času $2007-$ 2013

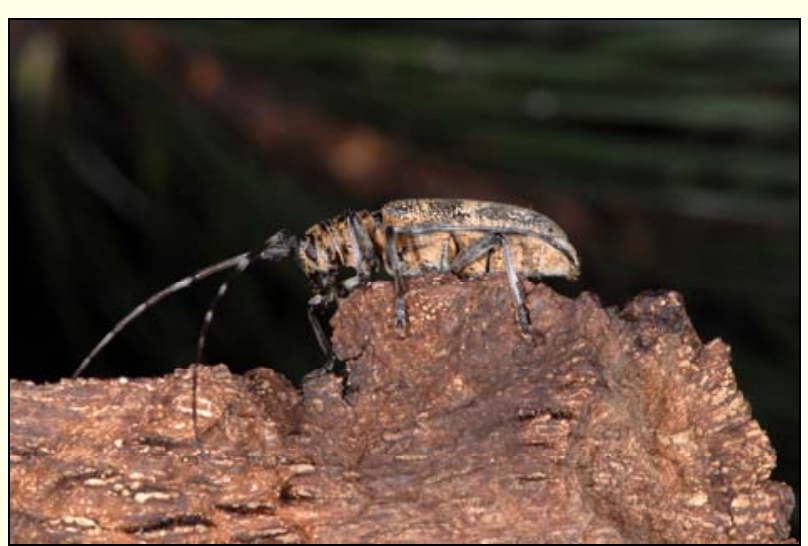

Slika 2: Monochamus galloprovincialis (Olivier, 1795) - borov žagovinar (Foto: M. Jurc)

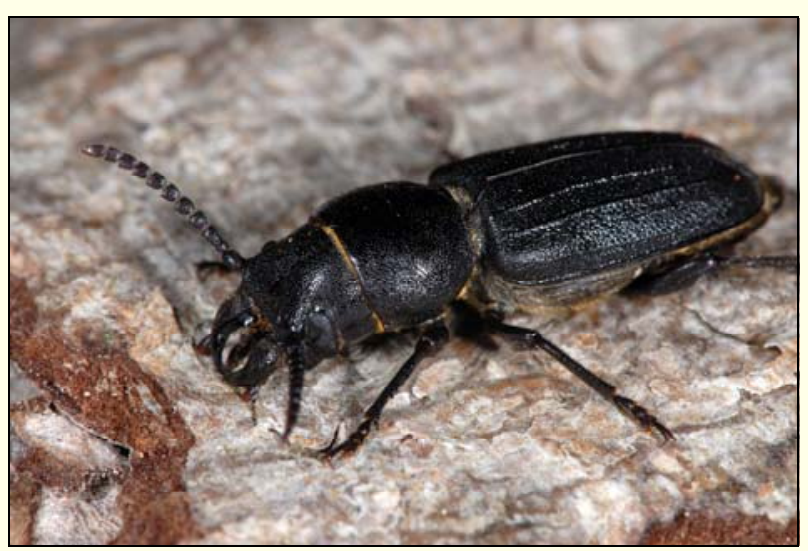

Slika 4: Spondylis buprestoides (Linnaeus, 1758) - gozdni kozliček (Foto: D. Jurc)

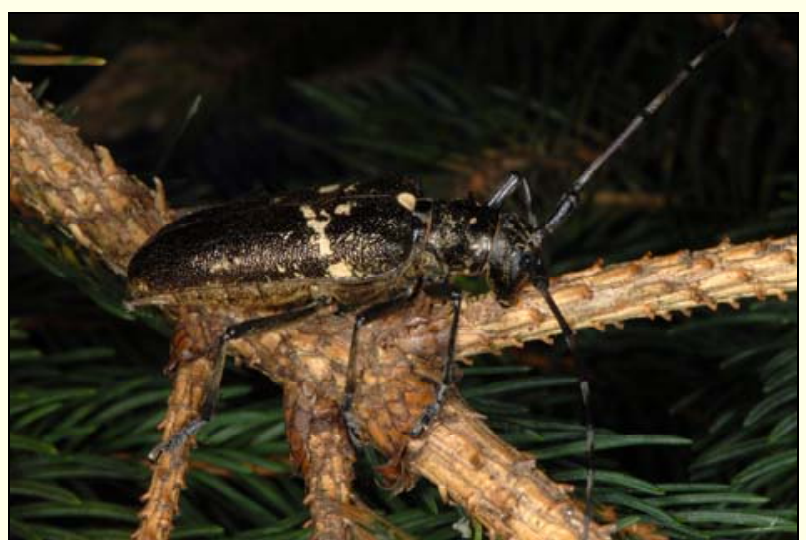

Slika 3: Monochamus sartor (Fabricius, 1787) - krojaški žagovinar (Foto: D. Jurc) 